\title{
“AQUI, ELES FALA ASSIM": UMA ANÁLISE SOCIOLINGUÍSTICA DA VARIAÇÃO DA CONCORDÂNCIA VERBAL EM PINHEIRO-MA
}

\author{
Israel Ferreira Santos ${ }^{*}$ \\ Georgiana Márcia Oliveira Santos*
}

\begin{abstract}
RESUMO: Alguns estudos já demonstraram que a variação da concordância verbal de terceira pessoa do plural no português brasileiro ocorre devido à influência tanto de variáveis linguísticas quanto de variáveis extralinguísticas. Nesse sentido, este trabalho tem como objetivo investigar as variáveis sociais que influenciam a realização da não concordância verbal de terceira pessoa do plural (doravante NCV3PP) no português falado em Pinheiro, no estado do Maranhão. Seguindo os pressupostos teórico-metodológicos da Sociolinguística (LABOV, 2008; TARALLO, 2007), pudemos constatar que, em Pinheiro, a variável sexo foi a que se mostrou mais relevante para a realização da NCV3PP.
\end{abstract}

PALAVRAS-CHAVE: Concordância verbal de terceira pessoa do plural; Português maranhense; Sociolinguística.

\section{Introdução}

A concordância verbal no português falado no Brasil tem recebido considerável atenção de pesquisadores de diversas partes do país. No que tange, especificamente, à concordância verbal de terceira pessoa do plural (doravante CV3PP), o trabalho pioneiro de Lemle e Naro (1977), sobre a concordância verbal na fala dos cariocas, impulsionou várias pesquisas no país a fim de se investigar as variáveis linguísticas e extralinguísticas que geram a ocorrência da variação desse fenômeno.

Nesse sentido, nosso trabalho vem somar-se a essas pesquisas, pois tem o objetivo de investigar as variáveis sociais - mais especificamente, sexo e idade ${ }^{1}$ - que influenciam a

\footnotetext{
* Mestrando em Letras pela Universidade Federal do Maranhão. Membro do Grupo de Estudos e Pesquisas em Línguas, Memórias, Identidades e Culturas (Gelmic/Ufma).

** Professora do Departamento de Letras da Universidade Federal do Maranhão (Ufma). Professora Permanente do Programa de Pós-Graduação em Letras (PPGLetras) da Ufma. Coordenadora do Grupo de Estudos e Pesquisas em Línguas, Memórias, Identidades e Culturas (GELMIC). Pesquisadora permanente do Projeto Atlas Linguístico do Maranhão (ALiMA).

1 A escolha dessas duas variáveis sociais deveu-se ao fato de que muitos estudos controlaram essas duas variáveis nas investigações sobre a CV3PP no Brasil (CARVALHO, 2018; OLIVEIRA, 2005; FARIA, 2008;
} 
realização da não concordância verbal de terceira pessoa do plural (doravante NCV3PP) no português falado em Pinheiro, no estado do Maranhão. Para tanto, evidenciamos que, neste estudo, consideramos: I) formas verbais padrão como aquelas que estão de acordo com as regras de concordância verbal estabelecidas pela gramática normativa; II) e, opostamente, formas verbais não-padrão como as que não atendem às prescrições dessa gramática. Os excertos, a seguir, retirados do nosso corpus de análise, exemplificam como essas duas formas se apresentam, respectivamente: I) “As palavra deles $\underline{\text { são }}$ muito rastada, sabe como é que é?” (Homem, faixa etária I); II) "Um momento muito importante pra mim foi quando meus, meus filho estudava que se formaro, né?" (Mulher, faixa etária II).

Tendo em vista que utilizamos o banco de dados do projeto Atlas Linguístico do Maranhão (doravante ALiMA) para compor o corpus deste estudo, faz-se necessário esclarecermos que a escolha do município de Pinheiro deu-se por vários motivos: por ser o único ponto de inquérito do ALiMA situado na microrregião da Baixada Maranhense ${ }^{2}$; porque, conforme dados do último censo do Instituo Brasileiro de Geografia e Estatística (IBGE)/2010, Pinheiro é o município mais populoso dessa área geográfica; e, também, pela importância histórica e cultural desse município para o estado do Maranhão.

Para dar suporte à nossa análise, tomamos como base os pressupostos teórico-metodológicos da Sociolinguística variacionista, pautando-nos, sobretudo, em Labov (2008) e Tarallo (2007), para analisarmos a ação de grupos de variáveis extralinguísticas no condicionamento de variantes linguísticas.

Nossas hipóteses iniciais seguiram as tendências encontradas em muitos outros estudos realizados no Brasil sobre a CV3PP. Desse modo, acreditávamos que tanto o sexo quanto a faixa etária influenciariam o uso das formas verbais não-padrão de terceira pessoa do plural em Pinheiro.

Nossa hipótese para a variável sexo, mais especificamente, foi a de que, por existir um formalismo associado ao papel que a mulher exerce na sociedade, as informantes do sexo feminino seriam as que menos usariam as formas não-padrão de concordância verbal, enquanto os informantes do sexo masculino usariam mais essas formas verbais.

MONGUILHOTT, 2009), considerando a importância que têm para a análise desse fenômeno. E, ainda, ao fato de que essas duas variáveis foram pré-estabelecidas pelo projeto Atlas Linguístico do Maranhão para a recolha dos dados.

2 A Baixada Maranhense é uma região de aproximadamente $20.000 \mathrm{~km}^{2}$ que se caracteriza, geograficamente, por ser uma depressão em forma de uma extensa concha alongada (IMESC, 2013, p. 27) A importância de realizarmos uma investigação linguística no único município da Baixada Maranhense que foi ponto de inquérito do projeto ALiMA deveu-se, sobretudo, por ser essa região histórica e popularmente conhecida por apresentar particularidades linguísticas em relação ao português falado em outras regiões do Maranhão. 
Quanto ao fator etário, nossa hipótese foi a de que os informantes da faixa etária I (18 a 30 anos), por serem os mais jovens e, consequentemente, estarem mais propensos à conexão com os recursos tecnológicos, fariam menos uso de formas não-padrão, enquanto os informantes da faixa etária II (50 a 65 anos), por serem os mais velhos, sem tanto acesso a esses recursos, fariam mais uso da NCV3PP.

Para a realização desta investigação, utilizamos o banco de dados do projeto ALiMA coletados mediante aplicação de um questionário morfossintático, das perguntas metalinguísticas e dos temas para os discursos semidirigidos. Utilizamos o programa computacional Goldvarb X para fazer as rodadas dos dados, fundamentais para nos auxiliar na investigação do fenômeno em estudo.

Como resultados obtidos, destacamos que a única variável selecionada como, indiscutivelmente, significativa para o uso das formas verbais não-padrão em Pinheiro foi a variável sexo. A variável faixa etária não se mostrou relevante, visto que não foi selecionada nas rodadas dos dados.

\section{A concordância verbal no português brasileiro}

Sistematicamente variável, a concordância verbal tem sido um fenômeno muito estudado pela Sociolinguística, uma vez que evidencia um dos pontos mais polêmicos da gramática normativa (HORA; ESPÍNOLA, 2004, p. 218): as regras que são estabelecidas pela referida gramática não correspondem aos usos linguísticos que os falantes, efetivamente, fazem no dia a dia.

Quanto à conceituação, a concordância verbal, ainda que compreendida de distintas formas, é comumente vista como “um processo morfossintático” (GAMEIRO, 2009, p. 5556). Morfológico porque utiliza morfemas indicadores de relações gramaticais entre dois elementos, e sintático porque os termos apresentam relação de dependência entre si.

Dentre os estudos realizados sobre a concordância verbal no PB, a CV3PP tem recebido atenção desde os trabalhos pioneiros de Lemle e Naro (1977). Esses autores, ao analisarem as falas de mobralenses ${ }^{3}$ da cidade do Rio de Janeiro, concluíram que a regra de concordância verbal, ou seja, que a forma padrão ora era aplicada, ora não.

\footnotetext{
${ }^{3}$ É um termo utilizado para designar as pessoas que participavam do projeto Movimento Brasileiro de Alfabetização - MOBRAL. Esse projeto foi instituído pela Lei no 5.379 e teve início no dia 15 de dezembro de 1967, quando o governo da época assumiu o controle da alfabetização de jovens e adultos no país. Em Beluzo e Toniosso (2015) encontramos mais informações sobre esse projeto.
} 
Nesse estudo, foi constatado que os informantes usavam os mesmos verbos em uma mesma sentença, no entanto, ocorriam variações na forma como esses verbos eram flexionados dentro dessa mesma sentença. A partir desse estudo pioneiro, muitos outros foram desenvolvidos em distintas regiões do país: Scherre e Naro (1998), Oliveira (2005), Lucchesi (2006), Faria (2008), Monguilhot (2001, 2009), entre outros.

Para uma análise pertinente do fenômeno da variação da CV3PP no português falado do Brasil é necessário, portanto, que sejam considerados tanto fatores linguísticos - como saliência fônica, posição e distância do sujeito em relação verbo, presença/ausência do que relativo, traço semântico do sujeito - quanto fatores extralinguísticos, como idade, sexo, nível de escolaridade, faixa etária.

\section{As contribuições dos estudos sociolinguísticos}

A Sociolinguística é o ramo dos estudos linguísticos que se preocupa com a língua enquanto fenômeno social e cultural, isto é, é uma área de investigação que estuda a língua no seu uso real, levando em consideração as relações existentes entre os aspectos sociais, culturais e a estrutura linguística (CEZÁRIO; VOTRE, 2013, p. 141). É um modelo teórico-metodológico que tem como precursor o linguista americano William Labov.

A Sociolinguística surgiu a partir da década de 60 com a função de evidenciar as correlações existentes entre língua e sociedade a partir da análise dos usos concretos da língua, ou seja, dos usos do dia a dia, particularmente, da fala espontânea.

Os estudos, nessa perspectiva de investigação, contrariam os pressupostos que apregoam a homogeneidade linguística, pois provam que a variação é essencial à natureza das línguas humanas.

As formas linguísticas em variação em uma determinada comunidade de fala ${ }^{4}$ são denominadas de variantes linguísticas, definidas como formas alternativas de se dizer a mesma coisa em um mesmo contexto e com o mesmo valor de verdade (TARALLO, 2007, p. 08). Quanto à ocorrência das variantes, Tarallo (2007, p. 11-12) afirma que:

\footnotetext{
${ }^{4}$ Labov (2008, p. 188) considera que a comunidade de fala "não pode ser concebida como um grupo de falantes que usam todos as mesmas formas; ela é mais bem definida como um grupo que compartilha as mesmas normas a respeito da língua", nesse sentido, segundo o autor, o que interessa à pesquisa sociolinguística não é o indivíduo e sim a comunidade de fala, pois é nela que a variação e a mudança linguística se realizam. Guy (2001), a seu turno, amplia a concepção laboviana de comunidade de fala considerando que ela é um grupo de falantes que se constitui a partir dos seguintes critérios: I) compartilham traços linguísticos que distinguem este grupo de outro; II) se comunicam mais entre eles do que com os outros e III) compartilham normas e atitudes frente ao uso da língua.
} 
As variantes de uma comunidade de fala encontram-se sempre em relação de concorrência: padrão vs não-padrão; conservadoras vs inovadoras; de prestígio vs estigmatizadas. Em geral, a variante considerada padrão é, ao mesmo tempo, conservadora e aquela que goza do prestígio sociolinguístico na comunidade. As variantes inovadoras, por outro lado, são quase sempre não-padrão e estigmatizadas pelos membros da comunidade.

A título de exemplo, podemos afirmar que a concordância verbal no PB constitui uma regra variável, ou uma variável linguística que abrange duas formas variantes, a saber, uma forma que apresenta as marcas de concordância, ou seja, formas padronizadas, e outra que apresenta a ausência dessas marcas, ou seja, formas não-padronizadas.

Nos estudos sociolinguísticos, há o intuito de se descrever, de forma estatisticamente fundamentada um determinado fenômeno variável com o objetivo de analisar, apreender e organizar variantes linguísticas usadas por uma comunidade, correlacionando a essas variantes fatores internos e/ou externos à língua.

Isto posto, observamos um viés quantitativo nas investigações sociolinguísticas, em que dados são quantificados por programas computacionais como o Goldvarb X, que realiza cálculos estatísticos de frequência e probabilidade de aplicação de uma determinada variável.

Os estudos sociolinguísticos visam desvendar a aparente assistematicidade de um suposto caos linguísticos, que é o universo das variações, buscando revelar quais fatores podem, ou não, motivar tais variações. Dito isto, a variação linguística, segundo os estudos sociolinguísticos, é condicionada por fatores internos e externos à estrutura linguística. Dos fatores externos pertinentes ao estudo da variação, podem ser destacados o estilo de fala, a idade, o sexo, a escolaridade, a profissão, a classe social, dentre outros.

Estudos como os de Labov (2008, p. 281-282) provaram, por exemplo, que as mulheres geralmente adotam menos as variantes estigmatizadas:

Na fala monitorada, as mulheres usam menos formas estigmatizadas do que os
homens (LABOV, 1966a, p. 288) e são mais sensíveis do que os homens ao pa-
drão de prestígio.[...] Essa observação é confirmada inúmeras vezes em Fischer
(1958), em todo o trabalho de Shuy \& Fasoldem em Detroid, [...]Aqui, como em
toda parte, fica claro que as mulheres são mais sensíveis do que os homens aos
valores sociolinguísticos explícitos.[...] as mulheres se corrigem mais nitidamente
do que os homens nos contextos formais.

Fica evidente, portanto, que em qualquer comunidade de fala, há uma considerável variação de usos linguísticos entre seus indivíduos: as mulheres não falam, necessariamente, como os homens, os avós não falam como seus filhos e netos, indivíduos pertencentes à classe alta não falam como aqueles que pertencem à classe baixa, e assim por diante. Nesse sentido, a língua é um conjunto de variedades linguísticas, cabendo à Sociolinguística a tarefa 
de descrever e analisar, de forma sistemática, a variação existente em uma determinada comunidade, demostrando de que forma fatores sociais influem sobre ela.

\section{Pinheiro, a princesa da Baixada}

Popularmente conhecida como "a princesa da Baixada", a cidade de Pinheiro está localizada na mesorregião Norte do estado do Maranhão, em uma área conhecida como Baixada Maranhense. A escolha dessa localidade deveu-se ao fato de ser o único ponto de inquérito do ALiMA situado na microrregião da Baixada Maranhense - historicamente conhecida por apresentar particularidades linguísticas em relação ao português falado no Maranhão - por Pinheiro ser o município mais populoso dessa região geográfica e pela importância histórica e cultural que tem para o estado.

A fundação de Pinheiro é atribuída ao capitão Inácio José Pinheiro, que teria partido da cidade de Alcântara em busca de um local para a instalação de uma nova fazenda. No dia 30 de março de 1819, ao atingir os campos do Pericumã, o capitão teria cumprido o seu objetivo.

Com uma área territorial total de 1.512, $968 \mathrm{~km}^{2}$, o município limita-se ao norte com Santa Helena; ao sul, com os municípios de Pedro do Rosário, São Bento; a leste, com Bequimão, Peri-Mirim e Palmeirândia, Central do Maranhão e Mirinzal; e a oeste com Presidente Sarney e Santa Helena.

Segundo dados do último censo realizado pelo IBGE, em 2010, sua população era de 78.162 habitantes. Atualmente, segundo esse instituto, sua população está estimada em 83.777 habitantes. A economia de Pinheiro está centrada nas atividades agropecuárias, pesca, agricultura e no comércio.

\section{Procedimentos metodológicos}

Para o desenvolvimento deste trabalho, utilizamos a metodologia e o banco de dados do Projeto Atlas Linguístico do Maranhão (ALiMA), que segue a metodologia do Atlas Linguístico do Brasil (ALiB) ${ }^{5}$.

O ALiMA, projeto coordenado pela Profa. Dra. Conceição Ramos e que está em processo de desenvolvimento por pesquisadores da Universidade Federal do Maranhão (UFMA), objetiva oferecer subsídios não só ao ALiB como aos interessados nos estudos

\footnotetext{
${ }^{5}$ O Atlas Linguístico do Brasil (ALiB) é o maior empreendimento em Geolinguística do Brasil. Tem por meta a realização de um atlas geral do Brasil no qual seja apresentada e descrita a realidade linguística do país. Um dos objetivos desse grande projeto é descrever a realidade linguística do país, priorizando a identificação das diferenças diatópicas de natureza fônica, morfossintática, léxico-semântica, prosódica.
} 
linguísticos, de forma geral, possibilitando o conhecimento da realidade sociodialetal e cultural do estado do Maranhão. Por meio desse projeto, muitos dados de fala já foram recolhidos, gerando um amplo acervo do falar maranhense.

O projeto tem se voltado para estudar diversos fenômenos do português maranhense nos diferentes níveis de análise linguística. Destarte, objetiva um conhecimento geral e sistemático da realidade linguística maranhense que possa subsidiar a investigação de possíveis convergências e divergências existentes entre os falares que formam o português brasileiro (RAMOS et al., 2019, p. 23). O Quadro 1, a seguir, apresenta a rede de pontos do ALiMA.

Quadro 1 - Rede de pontos do Atlas Linguístico do Maranhão

\begin{tabular}{|c|}
\hline Mesorregião Norte Maranhense \\
São Luís (MA 01) \\
Raposa (MA02) \\
Pinheiro (MA 03) \\
\hline Mesorregião Sul Maranhense \\
Alto Parnaíba (MA 10) \\
Balsas (MA 09) \\
Carolina (MA 08) \\
\hline Mesorregião Leste Maranhense \\
Araioses (MA 14) \\
Brejo (MA 13) \\
São João dos Patos (MA 11) \\
Caxias (MA 12) \\
Codó (MA 17) \\
Mesorregião Oeste Maranhense \\
Imperatriz (MA 07) \\
Turiaçu (MA 04) \\
Carutapera (MA 05) \\
\hline Besorregião Centro Maranhense \\
Bacabal (MA 16) \\
Tuntum (MA 18) \\
\hline
\end{tabular}

Fonte: Elaborado pelos autores.

Dito isso, o nosso corpus se constitui de dados coletados com a aplicação do questionário ALiMA no município de Pinheiro, identificado por esse projeto como ponto de inquérito (MA 03). Todos os informantes foram submetidos às mesmas perguntas e o critério de aplicação foi o mesmo; tudo isso para garantir a confiabilidade dos dados obtidos. O inquérito foi elaborado e realizado a fim de possibilitar, do melhor modo possível, o entendimento dos informantes sobre as questões propostas. Com relação a esse ponto, Brandão (1991, p. 32) enfatiza a importância da homogeneidade na coleta e tratamento dos dados dos questionários: "Essa preocupação é muito pertinente para que os dados coletados possam ser trabalhados de forma científica". 
Os informantes são de ambos os sexos, pertencentes a duas faixas etárias: faixa etária I (18 a 30 anos) e faixa etária II (50 a 65 anos). Todos são naturais de Pinheiro e possuem apenas o nível fundamental de ensino. Cada informante respondeu a questionários pré-elaborados com questões de aspectos fonético-fonológico, semântico-lexical, morfossintático, prosódico, pragmático discursivo, metalinguístico, além de temas para o discurso semidirigido. Contudo, nem todos esses questionários foram explorados por nós.

Assim, não havendo no questionário morfossintático uma pergunta específica para a investigação do uso da terceira pessoa do plural que pudesse atender diretamente aos nossos objetivos, consideramos, além das respostas obtidas mediante aplicação do questionário morfossintático (QMS), as respostas obtidas mediante realização das perguntas metalinguísticas e proposição dos temas para os discursos semidirigidos.

Quanto ao tratamento dos dados, desde uma perspectiva sociolinguística de investigação, usamos a metodologia quantitativa que faz uso de programas computacionais para o tratamento dos dados coletados. Utilizamos, particularmente, o programa computacional Goldvarb X para a realização das rodadas de análise das variáveis consideradas. O programa foi utilizado para verificar a influência que as variáveis sociais consideradas, neste estudo, exercem sobre o fenômeno em foco. Com relação ao uso do programa computacional, Scherre e Naro (1997, p. 65) esclarecem que esse pacote estatístico fornece

pesos relativos associados aos diversos fatores dos grupos de fatores ou variáveis independentes consideradas, bem como a seleção destes grupos em função de sua relevância estatística para a variação do fenômeno analisado. Os pesos relativos atribuídos indicam o efeito que cada um dos fatores tem sobre as variantes do fenômeno linguístico analisado (a variável dependente).

Os pesos relativos são indicadores da probabilidade da realização de uma ou outra forma quando considerada uma determinada variável. Nesse sentido, pesos relativos medem mediante uma escala de zero a um (0-1) a influência de cada fator sobre a variante considerada. $\mathrm{O}$ valor 0 indica que tal variante não acontece quando o fator está presente, já o valor 1 indica que tal variante sempre ocorre quando o fator está presente (GUY; ZILLES, 2007, p. 239). Dessa forma, pesos relativos acima de 0.50 indicam favorecimento da variante em foco, abaixo de 0.50 apontam para o desfavorecimento da ocorrência dessa variante e próximos a 0.50 indicam a não influência do fator sobre a variante.

Quanto ao tratamento dos dados, inicialmente, foram feitas as codificações dos dados para rodagem no programa computacional. Em seguida, realizamos a rodada geral dos dados com todas as formas verbais (padrão e não-padrão) de terceira pessoa do plural identificadas nas respostas dos informantes. Como resultado, as formas verbais não-padrão mostraram-se 
mais evidentes na fala dos pinheirenses. Nesse sentido, consideramos apenas as formas verbais não-padrão como foco de nossa investigação. Nas rodadas seguintes, testamos em que medida as variáveis sexo e faixa etária condicionavam o uso das formas não-padronizadas, já que todos os informantes têm somente o nível fundamental.

\section{Resultados e discussões}

Considerando as respostas dadas ao questionário morfossintático, ao discurso semidirigido e às perguntas metalinguísticas, obtivemos um total de 137 formas verbais (padrão e não-padrão) de terceira pessoa do plural.

Após a rodada dos dados, as formas verbais não-padrão foram as mais recorrentes na fala dos informantes. Como resultado, a variável sexo foi a que representou maior favorecimento para o uso das formas verbais não-padrão. A variável faixa etária não se mostrou relevante para o uso dessas mesmas formas, não sendo, portanto, selecionada pelo programa. A seguir, apresentamos os resultados e as discussões para cada variável considerada.

\section{Distribuição geral dos dados}

Como demonstrado na Tabela 1, abaixo, obtivemos um total de 137 ocorrências de formas verbais (padrão e não-padrão) de terceira pessoa do plural. Desse total, apenas 18 realizações correspondem à forma padrão, o que equivale a 13,1\% do total; as 119 restantes representam as formas não-padrão, o equivalente a $86,9 \%$ do total.

Tabela 1 - Distribuição geral dos dados

\begin{tabular}{ccc}
\hline Variantes & $\mathbf{N}^{\mathbf{o}}$ de Ocorrências & $\mathbf{\%}$ \\
\hline Forma padrão & 18 & $13,1 \%$ \\
\hline Forma não-padrão & 119 & $86,9 \%$ \\
\hline Total & 137 & $100 \%$ \\
\hline
\end{tabular}

Fonte: Elaborada pelos autores.

Em relação aos resultados encontrados, é pertinente enfatizarmos que, ainda que a variável escolaridade não tenha sido testada em nossa investigação, uma vez que todos os informantes possuem apenas o nível fundamental de ensino, estudos realizados sobre CV3PP (MONGUILHOTT (2009); OLIVEIRA (2005); CARVALHO(2008)) já comprovaram que pessoas com alto nível de escolaridade tendem a utilizar as formas mais prestigiadas e aceitas, ou seja, as formas verbais padronizadas, enquanto pessoas com baixo nível de 
escolaridade tendem a utilizar as formas menos prestigiadas, ou seja, as não-padronizadas, isso se confirmou, de certa forma, em nosso estudo, visto que a realização de formas nãopadrão foi predominante entre os pinheirenses.

\section{Distribuição diassexual}

No que diz respeito aos usos da língua, estudos já indicaram que homens e mulheres fazem usos distintos da língua. Assim, sistemas inteiros de paradigmas podem sofrer variação quando considerado o sexo dos informantes.

Tendo em conta que consideramos apenas as variáveis sociais sexo e faixa etária para a análise do uso das formas verbais não-padronizadas de terceira pessoa do plural em Pinheiro, a variável sexo foi a que mais favoreceu ao uso nas rodadas do Goldvarb X.

$\mathrm{Na}$ Tabela 2, a seguir, podemos observar melhor a distribuição diassexual das formas verbais não-padrão em Pinheiro.

Tabela 2 - Distribuição diassexual das formas verbais não-padrão de terceira pessoa do plural

\begin{tabular}{ccc}
\hline Diassexual & Ocorrências/Total & Peso Relativo \\
\hline Homem & $76 / 81$ & 0.65 \\
\hline Mulher & $43 / 56$ & 0.28 \\
\hline Input: 0.89 & Significância: 0.17 & Range: 0.72 \\
\hline
\end{tabular}

Fonte: Elaborada pelos autores.

Em nosso estudo, os usos realizados por homens e mulheres se mostraram bastante diversos. A Tabela 2 mostra que, em relação à realização das formas verbais não-padronizadas de terceira pessoa do plural no município de Pinheiro, os homens foram os que mais fizeram uso delas. De um total de 119 formas, 76 delas foram empregadas por informantes homens, assim, o peso relativo obtido por esse grupo foi de 0.65 .

As mulheres, por sua vez, obtiveram um resultado diverso. De um total de 119 realizações de formas verbais não-padrão em terceira pessoa do plural, apenas 43 delas foram realizadas por informantes mulheres, sendo que, para esse grupo, o peso relativo alcançado foi de 0.28. Considerando os pesos obtidos, ficou evidente que as formas verbais não-padrão foram mais usadas pelos informantes homens.

Nesse contexto, importa-nos ressaltar que Faria (2008), que investigou a CV3PP na cidade de Belo Horizonte, constatou que as mulheres fazem mais uso das formas verbais padrão do que os homens. O peso relativo encontrado para as elas, foi de 0.52 e, para eles, 
foi de 0.47. Outros estudos também demonstraram que, no PB, as mulheres são mais favorecedoras da manutenção das formas verbais padrão dos verbos (SCHERRE; NARO (1997), MONGUILHOT (2001)).

Corroborando as conclusões desses estudos, os resultados obtidos em nossa investigação, na cidade de Pinheiro, ressaltam uma tendência de uso da forma não-padrão mais pelos homens do que pelas mulheres.

Uma das justificativas possíveis para o menor uso das formas não-padrão pelas mulheres pode estar atrelada ao fato de que existe um formalismo associado ao papel da mulher na sociedade. No seio familiar, ainda cabe à mulher a responsabilidade pela educação dos filhos e pelo cuidado com a casa e com o esposo. Então, recaem sobre a mulher responsabilidades e posturas que são cobradas socialmente. Para atender satisfatoriamente a essa imposição social, ela tentará utilizar as formas linguísticas mais prestigiadas socialmente. Esse comportamento linguístico das mulheres desempenha um papel muito importante, uma vez que elas tendem a colaborar para a manutenção das formas linguísticas mais prestigiadas (LABOV, 2008).

Apesar de todos os nossos informantes possuírem apenas o nível fundamental de ensino, foram elas as que menos preservaram as formas verbais de terceira pessoa do plural não-padronizadas, confirmando, assim, o que tem sido uma tendência nos estudos linguísticos, quando considerado o sexo dos informantes.

\section{Distribuição diageracional}

Muitos trabalhos têm demonstrado que a idade, além de ser um importante fator para a interação e para a organização social, também é um evidenciador da variação e da mudança linguística. Como esse fator não foi considerado relevante nas rodadas do programa Goldvarb X, nossa análise baseou-se apenas no percentual obtido em cada uma das faixas etárias controladas: faixa etária I (18 a 30 anos) e faixa etária II (50 a 65 anos).

Os dados constantes na Tabela 3, abaixo, revelaram não haver diferença significativa de uso das formas verbais não-padrão de terceira pessoa do plural por informantes dessas duas faixas etárias.

Tabela 3 - Distribuição diageracional das formas verbais não-padrão de terceira pessoa do plural

\begin{tabular}{ccc}
\hline Diageracional & Ocorrências/Total & \% \\
\hline Faixa $\boldsymbol{I}$ & $57 / 64$ & $89 \%$ \\
\hline Faixa $\boldsymbol{I I}$ & $62 / 73$ & $84 \%$ \\
\hline Input: 0.89 & & Significância: 0.17 \\
\hline
\end{tabular}


Com base nos valores obtidos para as duas faixas, não houve diferença sensível para o uso das formas verbais não-padronizadas entre os informantes mais jovens e os mais velhos. Os informantes pertencentes à faixa etária I (18 a 30 anos), ou seja, os mais jovens favoreceram, muito sutilmente, mais o uso das formas verbais não-padrão do que os informantes da faixa etária II (50 a 65 anos), ou seja, do que os mais velhos. O percentual atribuído ao grupo dos informantes mais jovens foi de $89 \%$ e o atribuído aos mais velhos foi de $84 \%$.

Como exposto na Tabela 3, os resultados evidenciam uma diferença sutil, apenas de cinco pontos percentuais, entre as duas faixas etárias analisadas. Nesse sentido, os nossos resultados corroboram o que tem sido uma tendência nos estudos da concordância verbal de terceira pessoa do plural quando observado o fator etário, ou seja, os informantes de idade mais avançada tendem a usar mais as formas verbais padrão, enquanto os mais jovens tendem a usá-las menos.

A título de exemplo temos Carvalho (2018), que investigou a concordância verbal de terceira pessoa em Quirinópolis - GO. Os dados revelaram que os informantes mais jovens (14 a 30 anos) - (31 a 45 anos) foram os que mais utilizaram as formas verbais não-padrão. Para esse grupo os percentuais foram bastante altos: 80\% e 67\%, respectivamente. O grupo de informantes mais velhos (46 a 65 anos) - (acima de 60 anos) foi o que menos utilizou as formas não-padrão; os percentuais atribuídos a eles foram de 54\% e 63\%, respectivamente.

O percentual de 80\% alcançado pelos mais jovens, no estudo, foi considerado muito alto pela pesquisadora, o que gerou a hipótese de que em Quirinópolis pode estar havendo um processo de mudança em direção à perda da marcação das formas verbais padrão da terceira pessoa do plural. Com relação a esse fator, Chagas (2014, p. 141) afirma que "quanto maior a diferença de idade, maior a probabilidade de encontrarmos diferenças na forma de falar de duas pessoas", ou seja, quanto maior for a diferença entre as faixas etárias dos falantes, maior será a tendência deles apresentarem traços distintivos em seus comportamentos linguísticos.

Com relação a Pinheiro, uma possível justificativa para o resultado alcançado em relação à variável faixa etária pode ser atribuída ao conservadorismo linguístico pelos mais velhos, ou seja, os informantes da faixa etária II tendem a usar, com menor frequência, variantes tidas como não-padrão, mostrando-se, dessa forma, mais resistentes à mudança. Os mais jovens, por sua vez, mostraram-se mais sensíveis ao uso das formas inovadoras, ou seja, das formas não-padrão e, nesse sentido, mais receptíveis ao uso dessas formas.

Uma possível motivação à receptividade dessas formas inovadoras, ou seja, as formas não padrão pode estar atrelada ao contato que os informantes da faixa etária I mantêm com 
os meios de comunicação. Todos os informantes da faixa etária I afirmaram que assistem à televisão e ouvem rádio todos os dias. Os informantes da faixa etária II, a seu turno, afirmaram que assistem apenas à televisão todos os dias, mas nunca ou raramente ouvem rádio.

Nesse sentido, com relação aos resultados encontrados em nosso estudo, consideramos que o maior índice de uso das formas verbais não-padrão de terceira pessoa do plural pelos jovens pode estar associado ao fato de eles estarem mais conectados com os avanços tecnológicos e, consequentemente, estarem em maior contato com as formas linguísticas inovadoras.

Os jovens estão mais expostos aos meios digitais, em outras palavras, são os mais inseridos nas redes de relações sociais intermediadas pelos meios de comunicação de massa como a televisão, o rádio e a internet. Essas relações, intermediadas pelas mídias sociais, possibilitam aos mais jovens não só um contato com outras culturas, como também com formas linguísticas inovadoras. Os mais velhos, por não estarem tão engajados nesses contextos comunicativos valorizados pelos mais jovens, tendem a preservar as formas linguísticas mais conservadoras, estando mais propensos a manterem o uso das formas verbais padrão.

\section{Considerações finais}

Os resultados alcançados, neste estudo, sobre a concordância verbal de terceira pessoa do plural no município de Pinheiro - MA, vêm somar-se a tantos outros encontrados pelo Brasil afora, ao considerarmos a influência que as variáveis sexo e faixa etária exercem sobre o uso das formas verbais não-padrão.

Quanto ao fator sexo, os nossos resultados corroboram os encontrados em Faria (2008), Scherre; Naro (1997), Monguilhot (2001), pois demonstram que os homens se mostraram mais favoráveis ao uso das formas verbais não-padrão de terceira pessoa do plural.

Assim, acreditávamos que em Pinheiro as mulheres seriam as que menos realizariam as formas verbais não-padrão devido ao formalismo associado ao papel exercido por elas na sociedade. Essa hipótese se confirmou, pois, nas rodadas dos dados, essa variável foi selecionada como favorecedora. Os pesos relativos atribuídos aos homens e às mulheres foram de 0.65 e 0.28 , respectivamente.

Quanto à variável faixa etária, acreditávamos que essa seria selecionada como relevante para o uso das formas verbais não-padrão, uma vez que os jovens, seriam os que mais preservariam as formas padrão de terceira pessoa do plural. No entanto, essa hipótese não foi 
confirmada. Contudo, achamos pertinente analisarmos os resultados obtidos considerando apenas os percentuais atribuídos a essa variável.

Desse modo, nossos resultados mostraram que, muito tenuamente, os informantes mais jovens realizam mais as formas não-padrão, como os de Carvalho (2018). Nesse sentido, os percentuais atribuídos em nossa investigação revelaram não haver diferença expressiva de uso das formas verbais não-padrão entre informantes das faixas etárias I e II. Os informantes da faixa etária I, foram os que mais favoreceram, muito sutilmente, o uso dessas formas verbais.

Por fim, destacamos que esta investigação não é categórica quanto aos resultados obtidos. Outras investigações necessitam ser realizadas sobre o fenômeno em Pinheiro a fim de evidenciarmos, de modo mais amplo, o comportamento da variação da concordância verbal de terceira pessoa do plural nesse município.

\section{“AQUÍ, ELLOS HABLA ASÍ": UN ANÁLISIS SOCIOLINGÜÍSTICO DE LA VARIACIÓN DE LA CONCORDANCIA VERBAL EN PINHEIRO-MA}

RESUMEN: Algunos estudios ya han demostrado que la variación de la concordancia verbal en tercera persona del plural en portugués brasileño ha ocurrido debido a la influencia de variables lingüísticas y variables extralingüísticas. En dicho sentido, este trabajo tiene como objetivo investigar en qué medida las variables sociales sexo y edad influyen en el desacuerdo verbal en tercera persona del plural (en adelante NCV3PP) en portugués hablado en Pinheiro, en el estado de Maranhão. Siguiendo los supuestos teórico-metodológicos de la Sociolingǘstica (LABOV, 2008; TARALLO, 2007), hemos comprobado que, en Pinheiro, la variable sexo fue la más relevante para la realización de la NCV3PP.

PALABRAS-CLAVE: Concordancia verbal en tercera persona del plural; Portugués maranhense; Sociolingüística.

\section{REFERÊNCIAS}

BELUZO, Maira. Ferreira.; TONIOSSO, José. Pedro. O mobral e a alfabetização de adultos: considerações históricas. Cadernos de Educação: Ensino e Sociedade, Bebedouro-SP, n. 2, p. 196-209, abr. 2015.

CARVALHO. Marilda A. Adão. Padrões morfossintáticos variáveis na fala de Quirinópolis-GO: a concordância verbal de terceira pessoa do plural - p6. Uberlândia, 2018. 147 p. Tese de doutorado. Instituto de Letras e Linguística, Universidade Federal de Uberlândia.

CEZÁRIO, M.M; VOTRE, S. Sociolinguística. In: MARTELOTTA, M. E. (Org.). Manual de Linguística. 2 ed. São Paulo: Contexto, 2013.

CHAGAS, P. A mudança linguística. In: FIORIN, J. L. (Org). Introdução à lingüística I: objetos teóricos. 6 ed. São Paulo: Editora Contexto, 2014, p. 141 - 163.

IMESC. Enciclopédia dos Municípios Maranhenses: microrregião geográfica da Baixada Maranhense. São Luís: 2013, 593p. v.2. Disponível em: < http://imesc.ma.gov.br/portal/Post/view/territoriais/84>. Acesso em: 19 jan. 2021. 
FARIA, Nicolle V. Moreira de. A concordância verbal no Português de Belo Horizonte. Belo Horizonte, 2008. 142 p. Dissertação de mestrado. Pontifícia Universidade Católica de Minas Gerais.

GAMEIRO. Maria Beatriz. A variação da concordância verbal de terceira pessoa do plural em redações escolares do ensino fundamental e médio: uma avaliação de fatores linguísticos e sociais. Araraquara, 2009. 220p. Tese de doutorado. Faculdade de Ciências e Letras, Universidade Estadual Paulista.

GUY, Gregory R.; ZILLES, Ana. Sociolinguística Quantitativa - instrumental de análise. São Paulo: Parábola Editorial, 2007.

HORA, Dermeval da.; ESPÍNOLA, Sandra. O paralelismo Lingüístico e sua atuação no processo variável da concordância verbo-sujeito. Revista da Abralin, v. 3, n.1-2, p.217-241, jul./dez. 2004.

IBGE - Instituo Brasileiro de Geografia e Estatística. Cidades e Estados. Disponível em: < https://cidades.ibge.gov.br/brasil/panorama>. Acesso em: 15 out. 2020.

LABOV, William. Padrões sociolinguísticos. Tradução Marcos Bagno, Maria Marta Pereira Scherre, Caroline Rodrigues Cardoso. São Paulo: Parábola Editorial, 2008.

LEMLE, Miriam; NARO, Anthony Julius. Competências básicas do português. Relatório final de pesquisa apresentado às instituições patrocinadoras Fundação Movimento Brasileiro de Alfabetização (Mobral) e Fundação Ford, 1977.

LUCCHESI, Dante. Parâmetros sociolingüísticos do Português do Brasil. Revista da Abralin, vol.5, n. 1 e 2, dez. 2006.

MONGUILHOTT, Isabel de Oliveira e Silva. Variação na concordância verbal de terceira pessoa do plural na fala dos florianopolitanos. Florianópolis, 2001. Dissertação de Mestrado, Universidade Federal de Santa Catarina.

Estudo sincrônico e diacrônico da concordância verbal de terceira pessoa do plural no PB e no PE. Florianópolis, 2009. 229 p. Tese de doutorado, Universidade Federal de Santa Catarina.

OLIVEIRA, Marian dos Santos. Concordância verbal de terceira pessoa do plural em Vitoria da Conquista: variação estável ou mudança em progresso? Salvador, 2005, 190 p. Dissertação de Mestrado. Instituto de Letras, Universidade Federal da Bahia.

RAMOS, Conceição de Maria de Araújo. et al. Estudos Sociodialetais do estado do Maranbão. São Luís: EDUFMA, 2019

SCHERRE, Maria Marta Pereira; NARO, Anthony Julius. Restrições sintáticas e semânticas no controle da concordância verbal em português. Fórum Lingüistico :Pós-Graduação em Lingüística, UFSC. Florianópolis:1 (45-71), 1998.

; _. A concordância de número no Português do Brasil: um caso de variação inerente. In: HORA, Dermeval. (org.) Diversidade lingüística no Brasil. João Pessoa: Idéia, 1997.

TARALlO, Fernando. A pesquisa sociolinguística. São Paulo: Ática, 2007.

Recebido em: 01/04/2021.

Aprovado em: 09/06/2021. 